\title{
Evaluasi Kinerja PLTMH Polohungo 40 KW Terhadap Small Scale Power Load (SSPL)
}

\author{
${ }^{1}$ Steven Humena, ${ }^{2}$ Frengki Eka Putra Surusa, ${ }^{3}$ Amelya Indah Pratiwi, \\ ${ }^{4}$ Rifat Kombu \\ 1,2,3,4Universitas Ichsan Gorontalo, Jl. Drs. Achmad Nadjamuddin No.10-Gorontalo, Indonesia \\ email: steven.humena@gmail.com
}

\begin{abstract}
Abstrak
Pembangkit Listrik Tenaga Mikrohidro (PLTMH) Polohungo di desa Polohungo Kecamatan Tolangohula Kabupaten Gorontalo mempunyai komponen-komponen yaitu saluran penyadap (intake), saluran pembawa (headrace), bak penenang (forebay), saluran pembuangan (tailrace), pipa pesat (penstock), turbin, sistem peralatan mekanik, sistem transmisi mekanik, generator. Seiring dengan kebutuhan daya listrik yang semakin meningkat dan keterbatasan kemampuan kapasitas pembangkit, sehingga oprasional pembangkit tersebut tidak optimal. Penelitian ini bertujuan melakukan evaluasi kinerja PLTMH $40 \mathrm{~kW}$ terhadap beban listrik di Desa Polohungo Kabupaten Gorontalo. Tahapan evaluasi diawali dengan perhitungan data parameter teknis peralatan, kemudian dibandingkan dengan hasil perhitungan berdasarkan data parameter hasil pengukuran. Hasil evaluasi menunjukkan bahwa kondisi keseluruhan komponen utama seperti Generator, Turbin dan sistem kontrol pembangkit masih bekerja dengan baik meskipun tidak ditemukan riwayat perawatannya. Perbandingan besar daya generator pada saat beroperasi dengan daya yang dibangkitkan berdasarkan perhitungan debit air desain turbin terdapat selisih daya sebesar $12,212 \mathrm{~kW}$ atau $55,03 \%$ dari besar daya yang dihasilkan secara teori. Sehingga PLTMH Polohungo tidak optimal dalam menanggulangi beban daya skala kecil (small scale power load), dimana besar daya yang dihasilkan oleh perhitungan teoritis lebih besar dari besar daya yang dihasilkan pada saat generator beroprasi dengan debit air 0,02865 m3/detik.
\end{abstract}

Kata kunci: Kinerja pembangkit; Debit air; PLTMH Polohungo; SSPL.

\begin{abstract}
The Polohungo Micro-hydro Power Plant (PLTMH) in Polohungo village, Tolangohula District, Gorontalo Regency has several components, namely intake, headrace, forebay, tailrace, penstock, turbines, mechanical equipment systems, mechanical transmission systems, and generators. The increase of demand for electrical power and the limited capacity of the generator was causing suboptimal plant operation. This study aims to evaluate the performance of the 40 kW PLTMH against the electrical load in Polohungo Village, Gorontalo Regency. The evaluation stage began with the calculation of the technical parameter data of the equipment, which was then compared with parameters obtained from measurement. The evaluation results show that the overall condition of the main components such as generators, turbines, and the generator control system was still working well even though there was no history of maintenance. There was a power difference of $12.212 \mathrm{~kW}$ or $55.03 \%$ between the real-world generated power and theoretically calculated power based on turbine design water flow. Therefore, PLTMH Polohungo was not operating optimally when handling small-scale power loads, where the amount of power generated by theoretical calculations is greater than the amount of power generated when the generator is operating with a water flow rate of $0.02865 \mathrm{m3} / \mathrm{second}$.
\end{abstract}

Keywords: generator performance; Water discharge; PLTMH Polohungo; SSPL. 


\section{Pendahuluan}

Sumber energi terbarukan memiliki potensi yang besar bila dimanfaatkan untuk menghasilkan energi listrik yang dapat dipakai di daerah-daerah yang terisolir. Desa mandiri energi (DME) merupakan salah satu program untuk pemenuhan kebutuhan energinya sendiri. Desa Mandiri Energi (DME) merupakan alternatif pemecahan masalah penyediaan energy, disamping itu pengembangan Program DME diharapkan dapat mengurangi tingkat kemiskinan (Pro-Poor), memperkuat ekonomi nasional (ProGrowth) dan memperbaiki lingkungan (Pro-Planet). Program ini dicanangkan pertama kali oleh Presiden RI pada tahun 2007. Kriteria dari desa mandiri energi adalah desa yang mampu memenuhi minimal $60 \%$ dari total kebutuhan energinya (listrik dan bahan bakar) dengan memberdayakan potensi sumber daya setempat serta tumbuhnya kegiatan produktif untuk meningkatkan perekonomian desa sebagai dampak dari ketersediaan energi lokal (Kariongan et al., 2019).

Dalam usaha meningkatkan mutu hidup dan pertumbuhan ekonomi masyarakat pedesaan, energi listrik memiliki peranan sangat besar (Syukrahmi et al, 2018). Ketersediaan listrik di pedesaan baik dikelola swasta maupun pemerintah akan mendorong peningkatan produktivitas, sarana keagamaan, pendidikan, kesehatan dan fasilitas umum lainnya (Sukamta \& Kusmantoro 2013).

Pada saat ini sudah banyak desa yang menikmati listrik tetapi hanya menggunakan sumber energi terbarukan dari matahari (Humena, Surusa, \& Anang 2018), padahal cukup besar potensi air yang belum termanfaatkan secara optimal. Pemanfaatan air sebagai energi baru dan terbarukan untuk membangkitkan energi listrik saat ini tengah berkembang, dimana selain digunakan untuk mendukung kehidupan, air juga dapat digunakan sebagai sumber tenaga primer PLTMH (Alamsyah et al., 2016; Nugroho, 2015; Riadi, 2016).

Untuk memaksimalkan pemanfaatan sumber tenaga primer PLTMH, selain dilihat dari sisi sosial, selayaknya pelaksanaan pembangunan PLTMH diikuti dengan pengujian dan evaluasi kinerja agar instalasi yang terbangun dapat berjalan dan memiliki kinerja yang optimum. Uji kinerja Peralatan elektro-mekanikal pada PLTMH pada dasarnya merupakan kewajiban pelaksanaan pembangunan PLTMH yang sekaligus dapat memberikan masukan strategis pada proses perancangan dan fabrikasi (Nafis et al., 2012). Penilaian kinerja sebuah turbin air umumnya mengacu pada aturan bahwa efisiensi sebuah mesin pembangkit dengan output daya listrik dan variasi tinggi jatuh air (head) terhadap jangkauan (range) tertentu harus memenuhi efisiensi yang sesuai dengan spesifikasinya. 
Pada awal beroprasinya PLTMH Polohungo pada tahun 2014, pembangkit tersebut bisa melistriki keseluruhan 70 unit sambungan dengan daya masing - masing 360 Watt per unit sambungan atau keseluruhan total beban 25,2 kW. Tetapi sekitar pada tahun 2017 debit air mulai berkurang, sehingga PLTMH polohungo tersebut sudah tidak maksimal lagi menanggulangi beban daya skala kecil (small scale power load) tersebut. Oleh karena itu perlu diadakan evaluasi kinerja PLTMH $40 \mathrm{~kW}$ terhadap beban listrik di Desa Polohungo Kabupaten Gorontalo.

\section{Metode}

Lokasi Penelitian yang ditinjau adalah Sistem Pembangkit Listrik Tenaga Mikrohidro (PLTMH) Polohungo di desa Polohungo Kabupaten Gorontalo. Komponen-komponen pada PLTMH yaitu saluran penyadap (intake), saluran pembawa (headrace), bak penenang (forebay), saluran pembuangan (tailrace), pipa pesat (penstock), turbin, sistem peralatan mekanik, sistem transmisi mekanik, generator.

Penelitian ini dilakukan menggunakan metode deskriptif dalam beberapa tahapan, sebagai berikut:

1. Tahapan pertama dimulai dengan pengumpulan data awal yaitu parameterparameter peralatan berupa debit air, tinggi jatuh air, volume bak penenang, spesifikasi generator untuk digunakan sebagai perhitungan potensi daya pada PLTMH (Pratama, Santoso, \& Utomo 2014).

2. Tahap kedua setelah menghitung potensi daya pada PLTMH Polohungo, kemudian mengukur tegangan dan arus yang dihasilkan oleh generator.

3. Tahap ketiga setelah didapatkan hasil perhitungan daya yang dibangkitkan generator kemudian dibandingkan dengan hasil perhitungan potensi daya berdasarakan parameter peralatan PLTMH ( $P_{\text {out }}$ ) (Doda \& Mohammad 2018).

4. Kemudian dari hasil perhitungan tersebut sehingga dapat menarik kesimpulan sebagai bahan evaluasi kinerja terhadap pasokan daya PLTMH Polohungo dalam menanggung kebutuhan small scale power load (SSPL) tersebut. 


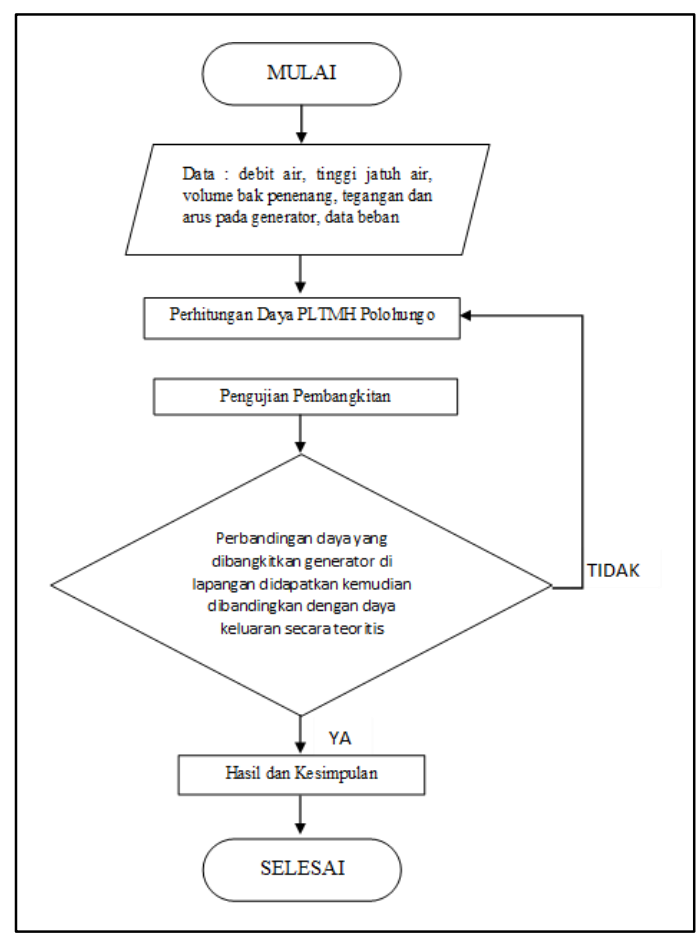

Gambar 1. Flowchart Metodologi Penelitian

\section{Hasil dan Pembahasan}

Hasil

Desa Polohungo adalah salah satu desa yang terletak di wilayah Utara Kabupaten Gorontalo, dengan luas wilayah $\pm 36 \mathrm{Km}^{2}$ yang terbagi dalam 4 Dusun. Batas wilayah sebelah utara yaitu desa Manano, sebelah timur yaitu desa pilomonu dan sebelah selatan dan barat yaitu desa Bina jaya.

Bentuk struktural kemiringan lereng 25-40 \% dengan curah hujan 378 mm/tahun, serta topografi yang tinggi. Jarak dari ibu kota Provinsi Gorontalo ke desa polohungo $\pm 115 \mathrm{Km}$, dengan jumlah penduduk 1205 Jiwa 340 KK pada tahun 2019 (Kabupaten Gorontalo, 2020).

Data spesifikasi teknis yang didapatkan dilapangan yaitu terlihat pada Tabel 1.

Tabel 1. Spesifikasi Teknis PLTMH Polohungo

\begin{tabular}{|c|c|c|}
\hline No. & Uraian & Spesifikasi \\
\hline \multirow[t]{5}{*}{1} & Bendung, dimensi : & \\
\hline & - Panjang Bendung & $15 \mathrm{~m}$ \\
\hline & - Lebar Mercu & $0,5 \mathrm{~m}$ \\
\hline & _ Jumlah Pilar & $1 \mathrm{bh}$ \\
\hline & - Lebar Pembilas & $1 \mathrm{~m}$ \\
\hline \multirow[t]{3}{*}{2} & Intake, dimensi : & \\
\hline & - Lebar & $60 \mathrm{~cm}$ \\
\hline & - Tinggi & $80 \mathrm{~cm}$ \\
\hline \multirow{4}{*}{3} & Saluran Pembawa, dimensi : & \\
\hline & - Lebar & $60 \mathrm{~cm}$ \\
\hline & - $\quad$ Tinggi & $60 \mathrm{~cm}$ \\
\hline & - Panjang & $14 m$ \\
\hline
\end{tabular}


$4 \quad$ Bak Penenang, dimensi :

- Panjang $7 \mathrm{~m}$

- Lebar $1,7 \mathrm{~m}$

- Tinggi 1,3

5 Penstock plat besi, dimensi :
$\quad$ - Panjang

- Diameter 10 Inchi

- Tebal $3 \mathrm{~mm}$

$95 \%$

Crossflow T-14

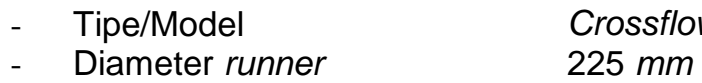

- Lebar runner $\quad 70 \mathrm{~mm}$

- Debit desain 60 Liter/detik atau 0,06 $\mathrm{m}^{3} /$ detik

- Net Head $65 \mathrm{~m}$

- Efisiensi $70 \%$

7 Transmisi Mekanik :

- Jenis Transmisi Belt \& Pully

- Belt

- Efisiensi

- Rasio Flat-Belt $30 \times 3178 \mathrm{~mm}$, GT 40

$98 \%$

$1: 1$

8 Generator :

- Tipe/Jenis MJB 200 SA

- Putaran $1500 \mathrm{rpm}$

- Kapasitas $50 \mathrm{kVA} / 40 \mathrm{~kW}$

- Tegangan 3 Fasa 380/220 Volt

- Frekuensi $50 \mathrm{~Hz}$

- Faktor Daya $\quad 0,8$

- Efisiensi $89 \%$

9 Ballast Load
- Tipe
- Rating Power
Air Heater
$50 \mathrm{~kW}$

10 Instalasi Rumah

- Jumlah sambungan 70 Sambungan

- Kapasitas daya/sambungan 450 VA atau 360 Watt

Data pengukuran yang dilakukan pada PLTMH Polohungo tanggal 28 Juni 2020, pukul 12.30 WITA untuk pengukuran waktu pengisian air bak penenang dan pukul 12.45 WITA untuk pengukuran Tegangan, Arus dan Frekuensi pada generator, seperti yang terlihat pada Tabel 2.

Tabel 2. Data Pengukuran Pada PLTMH Polohungo

\begin{tabular}{cl}
\hline No. & \multicolumn{1}{c}{ Uraian } \\
\hline 1 & Tegangan Fasa Pada Generator : \\
& VR-N $: 226,4$ Volt \\
& V $_{\text {S-N }}: 225,4$ Volt \\
& V 2 T-N 224,9 Volt \\
2 & Arus Pada Generator : \\
& IR $: 18,2$ Amper \\
& Is $: 18,6$ Amper \\
& IT : 18,5 Amper \\
3 & Frekuensi Pada Generator : \\
& $50 \mathrm{~Hz}$ \\
4 & Waktu Pengisian Air Bak Penenang : \\
& 9 Menit \\
\hline
\end{tabular}




\section{A. Perhitungan Debit Air (Q)}

Dalam perhitungan debit air (Q) pada PLTMH Polohungo dilakukan dengan cara perhitungan volume dari dimensi bak penenang dengan pengukuran waktu pengisian air pada bak sebagai berikut :

Volume bak Penenang: $v=\mathrm{P} \times \mathrm{L} \times \mathrm{T}$

$$
\begin{aligned}
& =700 \mathrm{~cm} \times 170 \mathrm{~cm} \times 130 \mathrm{~cm} \\
v & =15.470 .000 \mathrm{~cm}^{3} \\
v & =15,47 \mathrm{~m}^{3}
\end{aligned}
$$

Waktu Pengisian Air $\quad t=9$ Menit $=540$ Detik

$Q=\frac{v}{t}=\frac{15,47}{540}=0,02865 \mathrm{~m}^{3} /$ detik

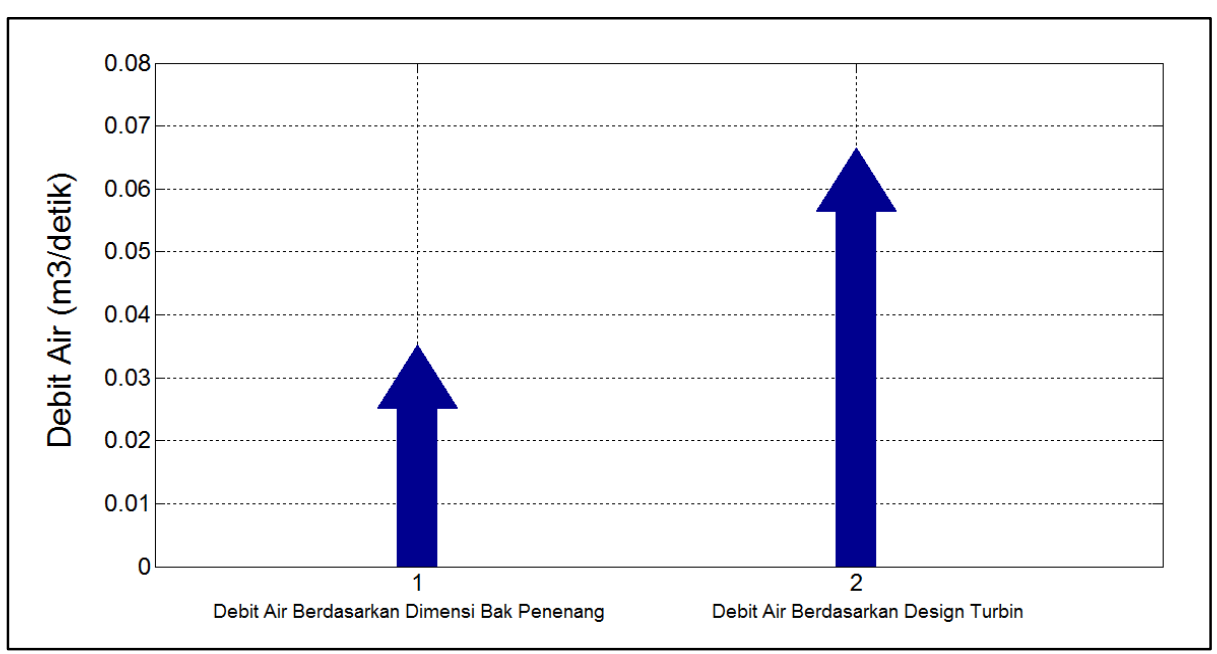

Gambar 2. Grafik Perbandingan Debit Air

B. Perhitungan Daya PLTMH Polohungo

Perhitungan daya pada PLTMH Polohungo menggunakan debit air pengisian bak penenang 0,02865 $\mathrm{m} 3 /$ detik dan debit air desain turbin 0,06 $\mathrm{m}^{3} /$ detik, dengan net head 65 meter, efisiensi turbin crossflow $\left(\eta_{\mathrm{tb}}\right) 70 \%$, efisiensi dari pipa pesat $\left(\eta_{\mathrm{pp}}\right) 95 \%$, efisiensi transmisi mekanik $\left(\eta_{\mathrm{tm}}\right) 98 \%$ dan efisiensi generator $\left(\eta_{\mathrm{g}}\right) 89 \%$.

1) Perhitungan Daya berdasarkan Debit Air Pengisian Bak Penenang

- Besar Daya Hidrolik :

$$
\begin{aligned}
& P_{h}=9,81 \cdot Q \cdot h \\
& P_{h}=9,81 \times 0,02865 \times 65 \\
& P_{h}=18,269 \mathrm{~kW}
\end{aligned}
$$

- Besar Daya Mekanik Turbin :

$$
\begin{aligned}
& P_{t b}=\eta_{p p} \cdot \eta_{t b} . P_{h} \ldots \ldots \ldots \ldots \\
& P_{t b}=0,95 \times 0,7 \times 18,269 \\
& P_{t b}=12,149 \mathrm{~kW}
\end{aligned}
$$


- Besar Daya Elektrik Generator :

$$
\begin{aligned}
& P_{\text {outBP }}=\eta_{t m} \cdot \eta_{g} \cdot P_{t b} \ldots \ldots \ldots \ldots \ldots \ldots \ldots \\
& P_{\text {outBP }}=0,98 \times 0,89 \times 12,149 \\
& P_{\text {outBP }}=10,596 \mathrm{~kW}
\end{aligned}
$$

Dari perhitungan daya berdasarkan debit air pengisian bak penenang ( $P_{\text {outBP }}$ ) didaptkan kapasitas daya yang mampu dihasilkan oleh besar daya hidrolik yaitu 18,269 $k W$, kemudian besar daya berdasarakan oleh mekanik turbin $12,149 \mathrm{~kW}$ dan besar total daya yang dihasilkan oleh generator yaitu 10,596 kW.

2) Perhitungan Daya Berdasarkan Debit Air Desain Turbin

- Besar Daya Hidrolik :

$$
\begin{aligned}
& P_{h}=9,81 . Q . h \ldots \ldots \ldots . . . \\
& P_{h}=9,81 \times 0,06 \times 65 \\
& P_{h}=38,259 \mathrm{~kW}
\end{aligned}
$$

- Besar Daya Mekanik Turbin :

$$
\begin{aligned}
& P_{t b}=\eta_{p p} \cdot \eta_{t b} \cdot P_{h} \ldots \ldots \ldots \ldots \\
& P_{t b}=0,95 \times 0,7 \times 38,259 \\
& P_{t b}=25,442 \mathrm{~kW}
\end{aligned}
$$

- Besar Daya Elektrik Generator :

$$
\begin{gathered}
P_{\text {outDT }}=\eta_{t m} \cdot \eta_{g} \cdot P_{t b} \ldots \ldots \ldots \\
P_{\text {outDT }}=0,98 \times 0,89 \times 25,442 \\
P_{\text {outDT }}=22,191 \mathrm{~kW}
\end{gathered}
$$

Sedangkan perhitungan daya berdasarkan debit desain Turbin $\left(P_{\text {outDT }}\right)$ didaptkan kapasitas daya yang mampu dihasilkan oleh besar daya hidrolik yaitu 38,259 kW, kemudian besar daya berdasarakan oleh mekanik turbin 25,442 kW dan besar total daya yang dihasilkan oleh generator yaitu 22,191 kW.

3) Perhitungan Kapasitas Daya Yang Dihasilkan Generator

$$
\begin{aligned}
P_{\text {outG }} & =\left(V_{R-N} \cdot I_{R} \cdot \cos \varnothing\right)+\left(V_{S-N} \cdot I_{S .} \cos \varnothing\right)+\left(V_{T-N} \cdot I_{T .} \cos \varnothing\right) \ldots \ldots \ldots \ldots \ldots . . \\
& =(226,4 \times 18,2 \times 0,8)+(225,4 \times 18,6 \times 0,8)+(224,9 \times 18,5 \times 0,8) \\
& =3296,384+3353,952+3328,52 \\
& =9978,856 \text { Watt } \\
& =9,979 \mathrm{~kW}
\end{aligned}
$$

Kapasitas daya yang mampu dihasilkan saat generator PLTMH Polohungo beroprasi dengan debit air 0,02865 $\mathrm{m}^{3} /$ detik yaitu sebesar 9,979 $\mathrm{kW}$. 


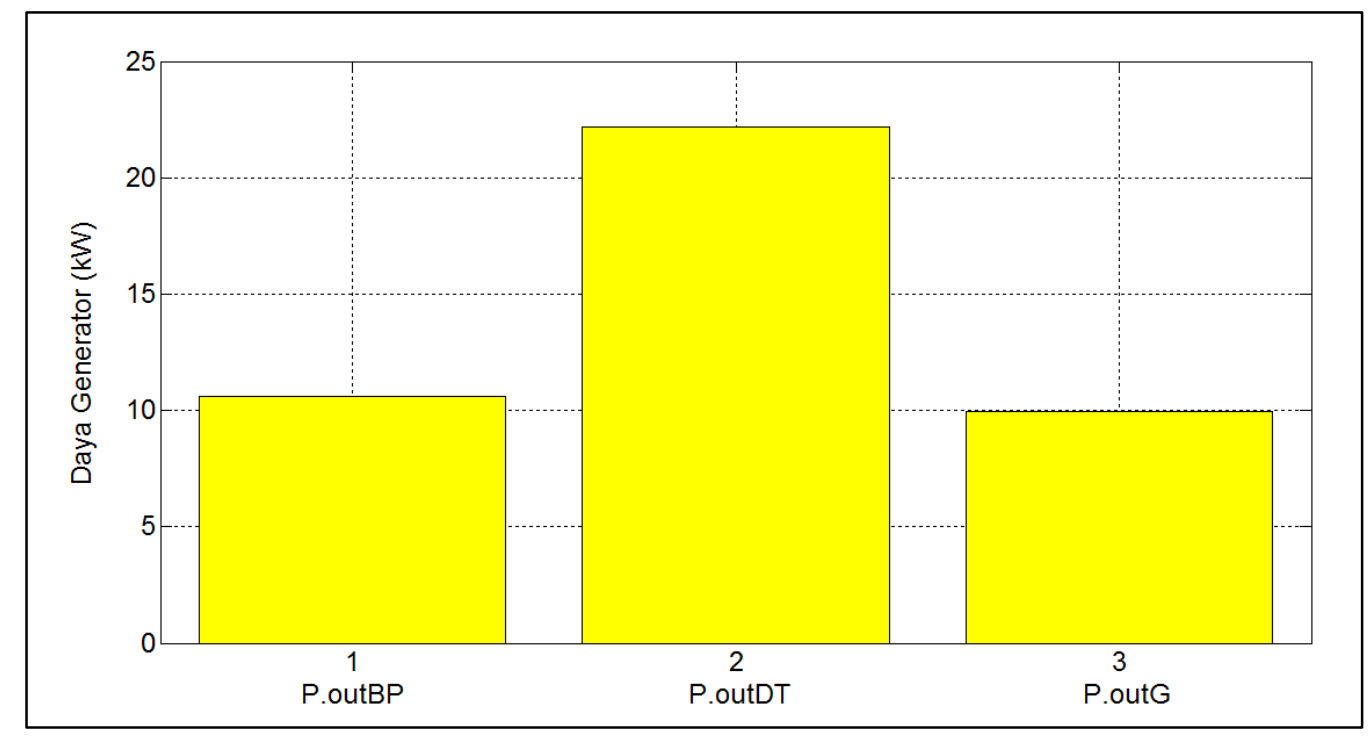

Gambar 3. Perbandingan Daya Generator

\section{Pembahasan}

Pada evaluasi kali ini, kondisi keseluruhan komponen utama seperti Generator, Turbin dan sistem kontrol pembangkit masih bekerja dengan baik meskipun tidak ditemukan riwayat perawatannya. Demikian dengan kondisi Air Heater sebagai Ballast Load masih bekerja dengan baik kecuali pada remote monitoring system yang sudah tidak bekerja dengan baik karena ada beberapa kabel terputus akibat gigitan tikus.

Konstruksi bangunan sipil yaitu bendung (weir), saluran headrace, bak pengendap atau bak penenang (Forebay), saluran pelimpah, pipa penstock, rumah pembangkit, dan tailrace masih berada dalam kondisi baik. Tetapi Pada saluran penyadap (intake) tidak tersedianya saringan yang berfungsi untuk menyaring sedimen apung. Hal ini menyebabkan sedimen apung bisa memasuki ke saluran pembawa dan saringan pada bak penenang perlu dilakukan perbaikan agar sedimen apung tersaring dengan baik sehingga kinerja turbin tidak terganggu.

Debit air yang mengalir untuk pengisian bak penenang tersebut adalah 0,02865 m3/ detik. Dari hasil perhitungan debit air tersebut terlihat bahwa ada perbedaan 0,03135 m3/detik dari debit desain turbin PLTMH Polohungo, perbandingannya terlihat pada Gambar 2, kemudian pada Gambar 3 perbandingan antara daya generator saat beroprasi $P_{\text {out } G}$ sebesar 9,979 kW dengan daya yang dibangkitkan berdasarkan teori debit air pengisian bak penenang sebesar $10,596 \mathrm{~kW}$, terdapat selisih daya sebesar 0,617 $\mathrm{kW}$ atau 5,82\% dari besar daya yang dihasilkan secara teori. Sedangkan perbandingan besar daya yang dihasilkan generator saat beroprasi $P_{\text {out }}$ dengan daya yang dibangkitkan berdasarkan teori debit air desain turbin sebesar 22,191 kW, terdapat selisih daya sebesar 12,212 $k W$ atau $55,03 \%$ dari besar daya yang dihasilkan secara teori. 
Menurut aparat dan masyarakat Desa Polohungo pada awal beroprasinya PLTMH Polohungo pada tahun 2014, pembangkit tersebut bisa memenuhi kebutuhan listrik keseluruhan 70 unit sambungan dengan daya masing - masing 300 Watt per unit sambungan atau keseluruhan total beban $21 \mathrm{~kW}$. Tetapi sekitar tahun 2017 debit air mulai berkurang, sehingga PLTMH polohungo tersebut sudah tidak maksimal lagi menanggulangi beban daya skala kecil (Small Scale Power Load) tersebut. Jadi dari kapasitas daya yang dihasilkan oleh generator $\left(\mathrm{P}_{\text {out }}\right)$ untuk menanggulangi beban daya skala kecil (Small Scale Power Load) hanya bisa menyuplai daya listrik ke 33 unit sambungan dari total 70 unit sambungan.

\section{Kesimpulan}

Dari hasil dan pembahasan PLTMH Polohungo, sehingga dapat menyimpulkan kondisi keseluruhan komponen utama PLTMH Polohungo seperti Generator, Turbin dan sistem kontrol pembangkit masih bekerja dengan baik meskipun tidak ditemukan riwayat perawatannya. Perhitungan debit air pengisian bak penenang lebih kecil 0,02865 $\mathrm{m} 3 /$ detik dari debit air desain turbin sebesar 0,06 m3/detik. Perbandingan besar daya generator pada saat beroprasi dengan daya yang dibangkitkan berdasarkan teori debit air desain turbin terdapat selisih daya sebesar $12,212 \mathrm{~kW}$ atau 55,03\% dari besar daya yang dihasilkan secara teori. Sehingga PLTMH Polohungo dapat disimpulkan tidak optimal dalam menanggulangi beban daya skala kecil (small scale power load), dimana besar daya yang dihasilkan oleh perhitungan teoritis lebih besar dari besar daya yang dihasilkan pada saat generator beroprasi dengan debit air 0,02865 m3/detik.

\section{Ucapan Terima Kasih}

Penulis mengucapkan terima kasih kepada DRPM KEMENRISTEK/BRIN atas dukungan finansialnya pada skema Penelitian Dosen Pemula Tahun 2019-2020 dengan nomor kontrak 30/SK/KP/LP-UIG/VIII/2020, kemudian Universitas Ichsan Gorontalo atas dukungannya dalam keikutsertaan dalam kegiatan ilmiah ini. Aparat serta masyarakat desa Polohungo Kecamatan Tolangohula Kabupaten Gorontalo yang telah menginjinkan dan membantu dalam pengambilan data penelitian ini sehingga tahapan proses penelitian terselesaikan dengan baik. Penulis juga berterima kasih kepada teman sejawat Dosen dan mahasiswa Program Studi Teknik Elektro Universitas Ichsan Gorontalo atas diskusinya yang bermanfaat.

\section{Daftar Pustaka}

Alamsyah, F., Notosudjono, D. \& Soebagia, H. (2016). Studi kinerja generator Pembangkit Listrik Tenaga Air Ubrug Sukabumi. 1-11.

Doda, N. \& Mohammad, H. (2018). Analisis potensi pengembangan pembangkit listrik. 
GJISE,

1(1),

1-10.

Retrieve

from

jurnal.unigo.ac.id/index.php/gjise/article/viewFile/134/131.

Humena, S., Surusa, F.E. P., \& Anang, H. (2018). Dampak masuknya PLTS Isimu 10 MW terhadap profil tegangan pada sistem kelistrikan $150 \mathrm{KV}$ Gorontalo. Dielektrika 5(2), 125-32. Retrieved from http://dielektrika.unram.ac.id/index.php/dielektrika/article/view/170.

BPS Kabupaten Gorontalo. (2020). Kecamatan Tolangohula dalam angka 2020. ed. BPS Kabupaten Gorontalo. Kabupaten Gorontalo: BPS Kabupaten Gorontalo.

Kariongan, J., Harun, N., Suyuti, A. \& Humena, S. (2019). Optimization of renewable energy generation to increase the electrification ratio in Borme District-Papua Province. ARPN Journal of Engineering and Applied Sciences, 14(4).

Nafis, S., Berlian, A., Anggono, T., \& Maksum, H. (2012). Evaluasi kinerja pembangkit listrik tenaga mikrohidro (PLTMH) studi kasus: PLTMH Kombongan, Kabupaten Garut, Jawa Barat, Evaluation on the performance of microhydro power plant (MPP). 11(1): 27-40.

Nugroho, A. (2015). Daya terserap Pembangkit Listrik Tenaga Mikro Hydro Karangtalun yang digabung dengan PT. PLN (Persero) Rayon Boja Area Semarang. 17(1): 30-34.

Pratama, F.M., Santoso, H. \& Utomo, T. (2014). Evaluasi kinerja Pembangkit Listrik Tenaga Mikro Hidro Bantal pada Pabrik Gula Assembagoes Kabupaten Situbondo. Jurnal Mahasiswa TEUB 2(1). Retrieved from http://elektro.studentjournal.ub.ac.id/index.php/teub/article/view/184/146.

Syukrahmi, R., Hidayat, \& Cahayahati. (2018). Studi kelayakan pengembangan pembangkit listrik tenaga minkrohidro lubuk tempurung kelurahan Kuranji kota $\begin{array}{llll}\text { Padang. } & \text { 12(1), } & 973 . & \text { Retrieved }\end{array}$ http://www.ejurnal.bunghatta.ac.id/index.php?journal=JFTI\&page=article\&op= view\&path\%5B\%5D=13147.

Muchlisin, R., (2016). Pembangkit Listrik Tenaga Mikro Hidro (PLTMH). Retrieved from https://www.kajianpustaka.com/2016/10/pembangkit-listrik-tenaga-mikroidro.html.

Sukamta, S., \& Kusmantoro, A. (2013). Perencanaan Pembangkit Listrik Tenaga Mikro Hidro (PLTMH) Jantur Tabalas Kalimantan Timur. Jurnal Teknik Elektro Unnes 5(2), 58-63. 